\title{
A interface arte-ciência-cultura como forma de inovar a formação inicial de professores de Física
}

\author{
Pedro Donizete Colombo Junior e Daniel Fernando Bovolenta Ovigli *
}

Resumo. Muitas são as possibilidades para a promoção de inovações na formação inicial de professores, porém poucas ações efetivamente têm se concretizado na prática em sala de aula da Educação Básica. 0 objetivo deste trabalho é contribuir com a formação inicial de professores de Física, ao apresentar e discutir uma proposta pedagógica inovadora, na perspectiva do desenvolvimento profissional docente, no contexto do curso de Licenciatura em Física da Universidade Federal do Triângulo Mineiro (UFTM), Minas Gerais, Brasil. Trabalhou-se especificamente nas disciplinas obrigatórias "Instrumentação para o Ensino de Física" (IEF) e "Orientação e Estágio Curricular Supervisionado IV" (ECS IV). São socializados os trabalhos desenvolvidos em diferentes temas da Física, vinculando-os à tríade arte-ciência-cultura, em uma abordagem avaliativa não fragmentada e fomentada por ações interdisciplinares e contextualizadas, com a finalidade de maximizar a atuação do futuro professor da disciplina, com um viés de inovação curricular, em âmbito avaliativo e metodológico. Buscou-se a elaboração e aplicação de um objeto educacional como forma de avaliação das ações dos futuros professores, na intersecção entre as disciplinas de IEF e ECS IV, na qual as temáticas discutidas em IEF fomentaram a aplicação em sala de aula em ECS IV. Conjetura-se que as ações propostas foram concretizadas integralmente, proporcionando novas vivências aos licenciandos em relação aos conceitos trabalhados na Universidade e culminando em inovações de natureza metodológica, curricular e avaliativa em sala de aula da Educação Básica, por meio de novas roupagens para temas tradicionais da Física.

Palavras-chave: investigação sobre currículos; formação de professores; ensino secundário; ciências da natureza.

\section{LA INTERFAZ ARTE-CIENCIA-CULTURA COMO FORMA DE INNOVAR LA FORMACIÓN INICIAL DE PROFESORES DE FISIICA}

Resumen. Muchas son las posibilidades para la promoción de innovaciones en la formación inicial de profesores, pero pocas acciones efectivamente se han concretado en la práctica en el aula de la Educación Básica. El objetivo de este trabajo es contribuir con la formación inicial de profesores de Física, al presentar y discutir una propuesta pedagógica innovadora, en la perspectiva del desarrollo profesional docente, en el contexto del curso de Licenciatura en Física de la Universidad Federal del Triângulo Mineiro

\footnotetext{
* Universidade Federal do Triângulo Mineiro (UFTM), Brasil.
} 
(UFTM), Minas Gerais, Brasil. Se trabajó específicamente en las disciplinas obligatorias "Instrumentación para la Enseñanza de Física" (IEF) y "Orientación y Pasantía Curricular Supervisada IV" (ECS IV). Se socializan los trabajos desarrollados en diferentes temas de la Física, vinculándolos a la tríada arte-ciencia-cultura, en un abordaje evaluativo no fragmentado y fomentado por acciones interdisciplinares y contextualizadas, con la finalidad de maximizar la actuación del futuro profesor de la disciplina, con un sesgo de innovación curricular, en ámbito evaluativo y metodológico. Se buscó la elaboración y aplicación de un objeto educativo como forma de evaluación de las acciones de los futuros profesores, en la intersección entre las disciplinas de IEF y ECS IV, en la cual las temáticas discutidas en IEF fomentaron la aplicación en el aula en ECS IV. Se concluye que las acciones propuestas se concretar íntegramente, proporcionando nuevas vivencias a los licenciandos en relación a los conceptos trabajados en la Universidad y culminando en innovaciones de naturaleza metodológica, curricular y evaluativa en el aula de la Educación Básica, por medio de nuevos ropajes para temas tradicionales de la Física.

Palabras clave: investigación curricular; formación de profesores; enseñanza secundaria; ciencias de la naturaleza.

THE ART-SCIENCE-CULTURE INTERFACE AS A WAY TO INNOVATE THE INITIAL EDUCATION OF PHYSICS TEACHERS

Abstract. There are many possibilities for the promotion of innovations in the initial teacher education, but few actions have effectively materialized in the classroom practice. The purpose of this paper is to contribute to the initial education of Physics teachers, presenting and discussing an innovative pedagogical proposal, in the perspective of professional development, in the context of the Physics undergraduate course at Federal University of Triângulo Mineiro (UFTM), Minas Gerais, Brazil. We worked specifically in the disciplines "Instrumentation for Physics Teaching" (IEF) and "Supervised Curricular Internship IV" (ECS IV). The work was developed in different themes of Physics, linking them to the art-science-culture triad, in a nonfragmented and evaluative approach and fostered by interdisciplinary and contextualized actions, is socialized with the purpose of maximizing the performance of the future teacher, with a bias of curricular innovation, in evaluative and methodological scope. We sought to elaborate and apply an educational object as a way of evaluating the actions of future teachers, at the intersection between the IEF and ECS IV, in which the themes discussed in IEF promoted the application in ECS IV. It is conjectured that the proposed actions were fully implemented, providing new experiences to the students in relation with the concepts worked in the University and culminating in methodological, curricular and evaluative innovations at school's classroom, through new dressings for traditional Physics.

Keywords: curriculum research; teacher education; secondary education; natural sciences. 


\section{REFLEXÕES ACERCA DE INOVAÇÕES NA FORMAÇÃO INICIAL DE PROFESSORES}

Apesar das inúmeras possibilidades para inovar a formação inicial de professores, poucas ações efetivamente têm se concretizado na prática pedagógica após a formatura. Destacam-se as dificuldades em empregar inovações curriculares, metodológicas e avaliativas em práticas docentes, além de currículos engessados com pouco, quiçá nenhuma abertura para novos conteúdos e práticas pedagógicas.

Quanto à formação inicial, compreendida como momento anterior ao ingresso na profissão, busca-se que os futuros docentes construam conhecimentos e competências relativas ao fazer educativo. No entanto, este momento formativo tem deixado a desejar no que tange à preparação de profissionais capazes de responder aos constantes desafios educacionais em um contexto social crescentemente complexo e exigente. Segundo Esteves (2016) é frequente um viés mais academicista, que privilegia um conjunto de conhecimentos que se referem aos conteúdos a serem ensinados e às Ciências da Educação, ainda que sem uma integração efetiva de tais conhecimentos, mesmo considerando que o período de formação inicial apresente um momento direcionado às práticas pedagógicas.

No que se refere à formação inicial do professor de Física no cenário brasileiro, vislumbram-se duas grandes reflexões: (i) tradicionalmente os cursos investem grande parte do tempo mostrando "O QUE ENSINAR", destinando pouco tempo (e disciplinas) para a discussão do "COMO ENSINAR" esta mesma Física na Educação Básica, ou seja, os meios pelos quais o professor poderá caminhar para a efetivação da ação em sua prática; (ii) a falta de diálogo entre as diferentes disciplinas dentro de um mesmo curso, por exemplo, componentes disciplinares classificadas como "Básicas" são apresentadas isoladamente de componentes classificadas como de "Ensino" ou de "Educação", além do fato da insistência em tentar desmembrar teoria e prática. Tais fatores têm reflexos diretos sobre a formação do licenciando, tanto que muitos têm deixado as Universidades sem preparo e qualificação para desempenhar suas atividades profissionais com excelência.

Nesse movimento de profissionalização, destaque-se haver autores como Roldão (2017), Dominguez e Garcia (2017) e Imbernón (2017) que optam por falar em desenvolvimento profissional. Dominguez e Garcia (2017) justificam o uso do termo pelo fato de denotar a concepção de profissional do ensino, além de a palavra "desenvolvimento" sugerir evolução e continuidade, rompendo com a tradicional justaposição entre formação inicial e continuada 
do professor. Assim, o desenvolvimento profissional é considerando como um processo contínuo de formação e aprendizagem ao longo da carreira docente, havendo reconhecimento da competência do professor para exercer a profissão.

Frente a estas questões e ao analisar a Física proposta pelos documentos oficiais brasileiros para a Educação Básica, o licenciado depara-se com outros fatores que influenciam diretamente sua prática e que dificultam qualquer forma de inovação (de conteúdo, de métodos ou de avaliação), como: volume excessivo de conteúdos, tempo limitado - apenas duas aulas semanais e, falta de infraestrutura das escolas. Coloca-se, então, na qualidade da formação inicial e criatividade docente uma das chaves para o posterior desempenho e desenvolvimento profissional. Assim, perguntas a respeito de quais são as propostas inovadoras desenvolvidas em âmbito de formação inicial tornam-se fundamentais no sentido de promover uma sólida formação e desenvolvimento de aprendizagens no cenário ibero-americano. Também se questiona em que medida as propostas de formação atual se ajustam às novas realidades e à incerteza que caracterizam a sociedade do conhecimento (Hargreaves, 2016).

Frente ao exposto, o objetivo deste artigo é contribuir com a reflexão acerca deste cenário educativo no contexto do ensino de Física, por meio da sistematização de ações que possam maximizar a atuação do futuro professor, com um viés de inovação curricular, avaliativa e metodológica para esta vertente disciplinar. No âmbito educativo, a inovação se respalda em um processo de mudança que demanda a implicação ativa de diferentes agentes educacionais e se materializa em transformações que impactam áreas bastante diferentes no contexto educacional. Para além de mudanças superficiais, buscam-se alterações de crenças, práticas e atitudes, voltandose à melhoria da qualidade da educação.

Para tanto, socializamos o trabalho realizado com diferentes temas vinculados à tríade arte-ciência-cultura, em uma abordagem não fragmentada e fomentada por ações interdisciplinares e contextualizadas com o cotidiano dos educandos. Desenvolvida no contexto do curso de Licenciatura em Física da Universidade Federal do Triângulo Mineiro (UFTM), Minas Gerais, Brasil, se insere na aproximação e diálogo entre as disciplinas obrigatórias "Instrumentação para o Ensino de Física" (IEF) e "Orientação e Estágio Curricular Supervisionado IV" (ECS IV), ambas ofertadas no último período do curso ( $8^{\circ}$ semestre).

Este trabalho se justifica por diferentes vieses, dentre os quais permite ao professor-formador (na Universidade) estreitar o diálogo entre a Universidade e a sociedade, por meio da Educação Básica, pesquisando e refletindo sobre novas formas de contribuir com a formação do licenciando. 
Busca-se que o licenciando, em processo de formação, vivencie novas formas de ensinar a Física, provocando o desejo em inovar a prática docente. E contribui com o (re)pensar a Educação Básica brasileira no momento em que o licenciando, em situação de regência no ECS IV, leva para as salas de aulas novas roupagens para temas tradicionais da Física e para os processos avaliativos desenvolvidos neste componente curricular.

\section{CONTEXTO EM QUE A PESQUISA ESTÁ INSERIDA}

A UFTM, campus Uberaba, desde sua fundação, em 1953, até o ano de 2005 funcionava como uma instituição de ensino superior especializada em cursos na área de saúde. Com a transformação em Universidade, a partir do Programa de Apoio aos Planos de Reestruturação e Expansão das Universidades Federais (REUNI), surgem as licenciaturas em Física, Química, Matemática, Ciências Biológicas, História e Geografia e, mais recentemente, a licenciatura em Educação do Campo (2013). Tendo como foco a licenciatura em Física, seu Projeto Pedagógico do Curso (PPC), ao descrever o perfil do egresso, menciona a busca em formar um profissional,

[...] com excelência para atuar nos quatro anos finais do Ensino Fundamental e no Ensino Médio da Educação Básica, de forma criativa, crítico-reflexiva, democrática, ética e comprometida com uma aprendizagem transformadora, a partir do domínio teórico-prático do seu campo de saber, tendo em vista o desenvolvimento do aluno em todas as suas dimensões (PPC/ Física/UFTM, 2010, p. 50, grifos nosso).

Acrescenta que, dentre as habilidades e competências perseguidas, almeja-se que o futuro professor egresso busque atuar de maneira interdisciplinar e "[...] fazer uso de diferentes linguagens em suas mais variadas manifestações: visual, corpórea, gestual, artística, oral, escrita, matemática, informacional, em diferentes situações" (p. 52-53, grifos nossos). Elementos estes que permitem corroborar e também justificar o trabalho aqui apresentado. Estas competências e habilidades se corporificam em um saber profissional, essencial à profissão docente, que é colocada em prática no ensino, particularmente da Física.

Para Roldão (2017), o percurso de construção de esse saber profissional é oriundo de uma mobilização complexa, organizada e coerente de todos os conhecimentos que gravitam ao redor de cada situação educativa ocorrente na escola, com o alcance do objetivo que define da ação profissional do professor: a aprendizagem do aluno. Moreira e Ramos (2016), nesta mesma linha, afirmam que embora seja fundamental o professor ter uma sólida preparação científica, não pode “dominar apenas o conteúdo que en- 
sina" uma vez que, muito além dos conhecimentos didáticos, são necessários conhecimentos mais amplos acerca do processo educativo e o papel da instituição escolar no mundo atual necessita, mais do que em outros momentos históricos, compreender e fazer presentes em suas práticas pedagógicas às relações entre o processo educativo, a escola e a cultura.

No que se refere à disciplina IEF, esta se insere no âmbito das disciplinas de ensino de Física e conta com uma carga horária de 90 horas-aula (h-a) ou 06 créditos, divididos em 30h-a presenciais de 50 minutos e 60h-a de atividades de planejamento e execução. Quanto à disciplina ECS IV, esta também se insere no âmbito das disciplinas de ensino de Física, e conta com uma carga horária de $120 \mathrm{~h}$-a ou 08 créditos, divididos em $15 \mathrm{~h}$-a presenciais de 50 minutos e 105h-a de planejamento e aplicação do estágio na escola.

Em consonância com os objetivos do curso, as disciplinas IEF e ECS IV buscam: (i) incentivar atividades de enriquecimento cultural, desenvolvendo práticas investigativas e utilizando metodologias, estratégias e materiais de apoio; (ii) promover o ensino da Física com estímulo à autonomia intelectual do aluno, valorizando a expressão de suas ideias e de seus saberes não científicos; (iii) propiciar o desenvolvimento de habilidades de reflexão e criação de artefatos de ensino aplicados à Educação Básica (PPC/Física/ UFTM, 2010, p. 50).

É justamente na elaboração e implementação de um objeto educacional (OE) que está à intersecção e o diálogo entre IEF e ECS IV aqui abordadas. Assim, o desafio foi desenvolver, a partir das temáticas discutidas em IEF, um OE a ser aplicado em sala de aula quando das regências dos licenciandos em ECS IV.

Não há uma definição consensual para OE, contudo pode ser entendido como suportes para o ensino, recursos didático-pedagógicos (digitais ou não) capazes de proporcionar e facilitar a compreensão dos conceitos em discussão. $\mathrm{O}$ uso de $\mathrm{OE}$ requer que o professor assuma o caráter de mediador do conhecimento, enquanto o aluno atue como sujeito ativo em seu processo de ensino e aprendizagem.

Em ambas as disciplinas esta integração tem sido desenvolvida pelo professor-formador desde o primeiro semestre de 2015. Neste artigo serão socializados os resultados das ações referentes ao primeiro semestre (2017/1) das disciplinas de IEF e ECS IV, ambas contando com 15 encontros presenciais, momentos de orientações e atividades extra-sala, além de acompanhamento de regências no ECS IV. Deste modo, para além da construção do saber 
profissional inerente ao futuro professor de Física, buscamos contribuir para que este desenvolva uma identidade profissional que lhe permita apropriar-se da cultura, valores e práticas característicos da profissão (Morgado, 2011).

Socializaremos os trabalhos realizados com os licenciandos em ambas as disciplinas e consequente aplicação por dois deles (aqui denominados Lic/Fis. F e Lic/Fis. L) na Educação Básica: um trabalho desenvolvido em 2016 na disciplina IEF e aplicado em 2017 na disciplina ECS IV em uma escola estadual de Uberaba/MG e, o segundo trabalho, também desenvolvido na disciplina IEF e aplicado na disciplina ECS IV, em 2017, em uma escola particular da mesma cidade.

Ainda que por vezes as situações de formação profissional de professores sejam centradas nos formandos, em sua ação educacional e nos contextos de trabalho, com experiências deveras positivas, muitas das vezes assenta-se em matrizes de natureza mais técnica, que veem o professor como "transmissor de conteúdos" (MORGADO, 2011). Nesta lógica, a competência profissional do docente se coloca em função de seu maior ou menor domínio de uma área científica e de competências na área pedagógica que facilitem a difusão destas informações. Tais fatores levaram Canário (2002, p. 60-61) a afirmar que os processos de formação inicial têm continuado "mais perto de modelos de produção de conformidade do que de modelos que apontem para a transgressão inovadora".

E com base nestes pressupostos é que deriva este trabalho, tendo em vista aumentar os níveis de percepção da Física e de sua relação com arte e cultura; ofertar atividades interativas relacionando arte-ciência-cultura por meio de análises de filmes, música, teatro, entre outros; contribuir com aspectos de dimensão pedagógica (professor-aluno, aluno-aluno, aluno-conhecimento) e dimensão epistêmica (ensino-aprendizagem de conhecimentos científicos) e suas aplicações na Educação Básica.

\section{CONTEÚDOS CURRICULARES E PROCEDIMENTOS DIDÁTICOS PRIORIZADOS}

Diferentes segmentos educacionais de nossa sociedade vêm discutindo, amplamente, as necessárias modificações na formação inicial do professor. As atividades didáticas realizadas buscaram preparar os licenciandos para o trabalho com conceitos da Física na interface arte-ciência-cultura. Desta forma, as estratégias desenvolvidas em IEF dialogam com as ações da disciplina ECS IV, em especial na aplicação de um OE no momento das regências dos licenciandos (Quadros 1 e 2). 


\section{QUADRO 1}

\section{Conteúdo e estratégias didáticas da disciplina IEF}

\section{Instrumentação para o Ensino de Física (IEF)}

"Os vários tipos de atividades experimentais na pesquisa em Ensino de Física. Produção de material didático experimental de baixo custo para o Ensino. Experimentos que promovam mudanças conceituais e a visão do Conteúdos curri- experimento como metodologias historicamente construídas, que encontra culares priorizados no aluno a possibilidade de sua própria elaboração e construção. Elaboração de livro-texto, vídeos interativos para a autoaprendizagem de Física. Inserção de observações astronômicas e construção de instrumentos para o Ensino de Astronomia" (PPC/Física/UFTM 2010, p. 155).

\section{Estratégias didáticas delineadas dos conteúdos priorizados}

- Trabalhos com atividades investigativas em âmbitos teóricos e práticos. Oficinas de construção de aparatos educacionais experimentais usando materiais de baixo custo.

- O uso de filmes, teatro e música como estratégias didáticas para o Ensino de Física. Análise de episódios e discussões conceituais.

- O uso de charges, tirinhas e literatura de cordel como estratégias didáticas para o Ensino de Física. Oficina de construção, a partir do uso de plataformas livres disponíveis na internet.

- Desenvolvimentos de Mapas conceituais (MC) e seu uso na educação. Oficina de elaboração de $\mathrm{MC}$ sobre temas diversos.

- $\mathrm{O}$ uso da metodologia Peer Instruction em discussões conceituais

\section{QUADRO 2}

\section{Conteúdo e estratégias didáticas da disciplina ECS IV}

\section{Orientação e Estágio Supervisionado IV (ECS IV)}

"Orientações para elaboração e implementação de projeto educacional (OE) na escola campo de estágio a partir das observações e reflexões realizadas.

Conteúdos curri- $O$ ensino de Física, a avaliação e o vestibular. Organização, seleção de culares priorizados material e elaboração das atividades docentes, a partir das observações, estudos teóricos e de diagnóstico realizado para imersão no campo de trabalho" (PPC/Física/UFTM 2010, p. 154-155).

\section{Estratégias didáticas delineadas dos conteúdos priorizados}

- Apresentação de diretrizes e discussão sobre relatórios de Estágio. Orientações para elaboração e aplicação de objetos educacional na escola, a partir das reflexões realizadas em IEF.

- Discussões teóricas sobre os elementos integrantes do estágio supervisionado em cursos de licenciatura - diferentes contextos. Discussão do Ser professor em início e no decorrer da carreira.

- Aportes teóricos sobre objetos educacionais (OE). Direcionamento para a elaboração de planos de aula visando à aplicação de objetos educacionais em sala de aula da Educação Básica.

- Aplicações de OE nas escolas. Organização, seleção de material e elaboração de relatórios das atividades docentes a partir das observações, dos estudos teóricos e de diagnóstico realizado para imersão no campo de estágio. Feedback das aplicações dos OE.

O procedimento didático-metodológico adotado para a pesquisa foi de natureza qualitativa (Laville e Dionne, 1999), na qual os licenciandos tiveram participação ativa na (re)construção dos conhecimentos científicos 
trabalhados no âmbito da intervenção. Como afirmam Araújo e Abib (2003), tal procedimento permite ao educando levantar e testar hipóteses, desenvolver a capacidade de observação, de descrição de fenômenos e de reelaboração de explicações causais para o observado.

Quando olhamos para a tríade arte-ciência-cultura vislumbramos a possibilidade de contribuir com a melhoria da formação do licenciando em Física, a partir do trabalho em diferentes vieses metodológicos. No presente caso, destacamos: (i) atividades investigativas e experimentais; (ii) teatro, música, cinema (Alves Ferreira, 2009; Ferreira, 2013, Napolitano, 2013); (iii) e literatura de cordel, charges, histórias em quadrinhos e tirinhas, além de sua aplicação em salas de aula. Buscamos, neste caso, romper com o que Pacheco (2016) menciona tratar-se de uma estrutura curricular organizada por disciplinas, isto é, um conhecimento compartimentalizado e fragmentado, fechado em fronteiras rígidas e em si mesmos e que em nada favorecem o diálogo interdisciplinar, bem como uma postura mais propositiva por parte dos professores em formação. Tais atividades, descritas a seguir, buscam detalhar os procedimentos didáticos utilizados com os licenciandos na disciplina IEF (na Universidade), ficando a aplicação de um destes "instrumentos" para o momento de regência na disciplina ECS IV (na Escola).

(i) Atividades investigativas e experimentais: 0 trabalho com atividades investigativas pelos licenciandos pode (re)significar o entendimento que têm sobre o ensino de Física, sendo um elo entre conceitos historicamente construídos e a forma de ensinar tais conceitos. Atividades investigativas possibilitam levantar e testar hipóteses, desenvolver a capacidade de observação, de descrição de fenômenos e de reelaboração de explicações causais para o observado (Araújo e Abib, 2003; Munford e Lima 2007; Carvalho, 2013).

Derivou das abordagens investigativas, o trabalho com atividades experimentais utilizando materiais de baixo custo e factíveis para que os licenciandos levassem para a sala de aula da Educação Básica. Em todas estas atividades era apresentado um problema e materiais para os licenciandos, os quais ficavam incumbidos de levantar e testar hipóteses para sua resolução. Desta forma, possibilitou-se aos licenciandos trabalhar com dados, testar hipóteses, construir explicações causais, interpretar resultados, elaborar conclusões e socializar com seus pares e professor-formador, sendo esta uma das formas de avaliação utilizadas pelo professor-formador (Figura 1). 
FIGURA 1

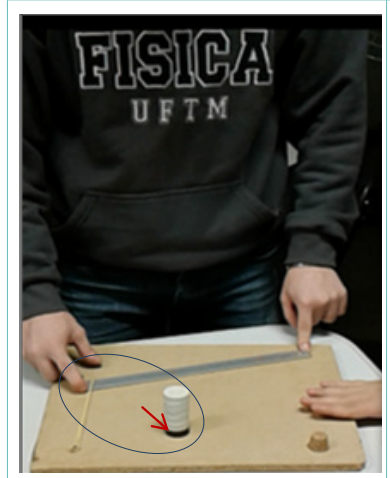

(a)

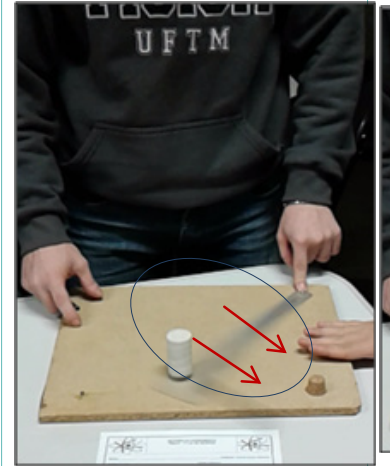

(b)

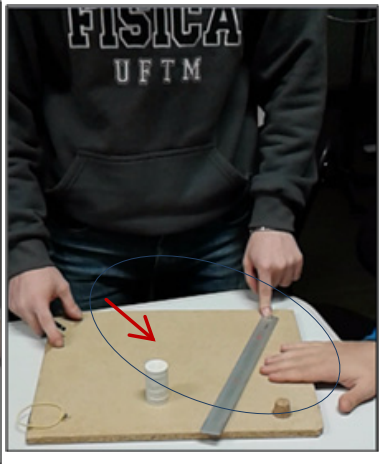

(c)

Em (a) é possível visualizar na ponta da seta vermelha uma peça na cor preta na base da torre. Em (b) o Lic/Fis. G solta a catapulta e torna-se possível visualizar a peça preta (borrão preto) saindo entre as setas vermelhas. Em (c) a torre permanece intacta, devido à $1^{\text {a }}$ Lei de Newton - Inércia, contudo sem a peça preta tornando possível discutir o conceito de Inércia.

DESCRIÇÃO DA ATIVIDADE: Esta atividade, com foco a ser aplicada no $2^{\circ}$ ano do Ensino Médio, foi conduzida por um licenciando em IEF, a partir dos estudos realizados. O objetivo foi discutir a $1^{a}$ Lei de Newton, a Lei da Inércia, por meio de atividade investigativa e utilizando materiais de baixo custo, passíveis de serem levados para a sala de aula em ECS IV.

Foto: professor-formador.

(ii) Teatro, música e cinema: As artes, em particular o uso de filmes de ficção científica, as encenações teatrais e a literatura, vêm sendo destacada por professores e pesquisadores como um recurso didático potencial e motivador para o ensino de Física (Piassi e Pietrocola, 2009). Diferentes temáticas da Física tornam-se possíveis de serem trabalhadas a partir de tais ferramentas, por exemplo: em filmes, como "A Máquina do Tempo" (ideia de viagem no tempo) e em músicas, como "Mais uma vez", interpretadas por Renato Russo (conceitos de Astronomia), além de teatros, séries e documentários. Desta forma, tais ações propiciaram um novo olhar e novas possibilidades para se ensinar Física, quando egressos da Universidade:

[...] compreender a Física como parte integrante da cultura contemporânea, identificando sua presença em diferentes âmbitos e setores, por exemplo, nas manifestações artísticas ou literárias, peças de teatro, letras de música, etc., estando atento à contribuição da ciência para a cultura humana (BRASIL, 2002, p. 15).

As temáticas teatro, música e cinema foram trabalhadas com os licenciandos em diferentes vieses em IEF, abarcando: contextos da História e Filosofia da Ciência e abordagens conceituais presentes nestes meios de entretenimento. Os licenciandos tiveram a oportunidade, por exemplo, de discutir conceitos da Física em diferentes filmes de ficção científica, iden- 
tificar elementos da ciência na música "Queremos Saber", de Gilberto Gil e, de discutir episódios da série The Big Bang Theory e praticar em sala de aula da Universidade antes de levar para a Educação Básica (Figura 2). Tais ações configuraram uma inovação metodológica para o ensino de Física e também forma avaliativa empregada pelo professor-formador.

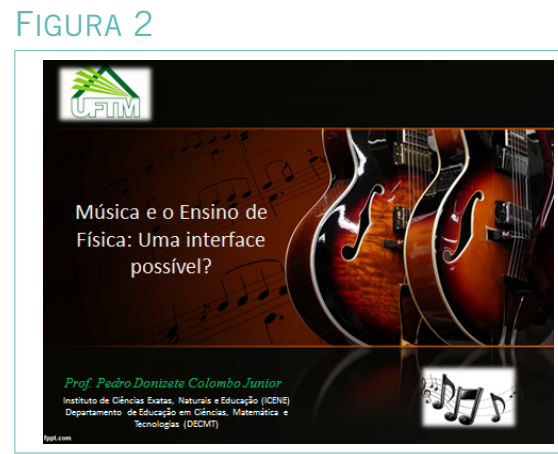

(a)

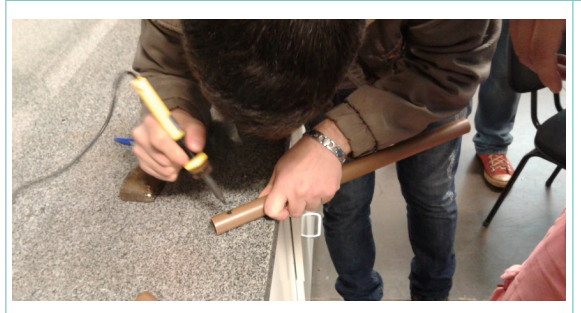

(c)

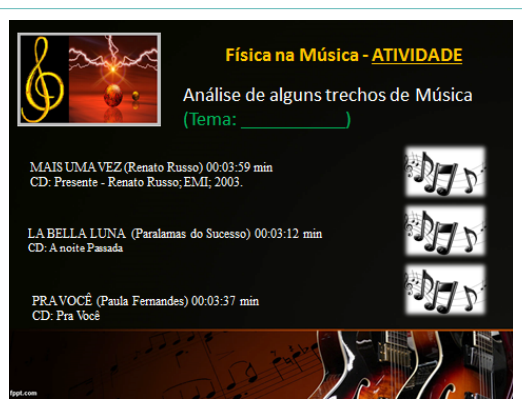

(b)

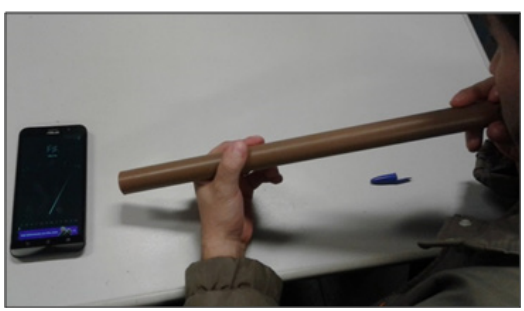

(d)

Em (a) e (b) trechos da aula sobre a temática música e o ensino de Física ministrada pelo professor-formador em IEF. Em (c) Lic/Fís. L realizando a construção de uma flauta com materiais de baixo custo a partir da aula sobre "Som e Acústica" por ele apresentada, como forma de avaliação integrada na disciplina de IEF. Em (d) Lic/Fís. L verificando a afinação do instrumento construído, a partir do uso de um aplicativo gratuito para celular. DESCRIÇÃO DA ATIVIDADE: Esta atividade com foco a ser aplicada no $2^{\circ}$ ano do Ensino Médio teve como objetivo reconhecer a Física como parte integrante da cultura humana, por meio da música, e realizar os estudos sobre os harmônicos musicais a partir da construção de uma flauta com materiais de baixo custo.

Foto: professor-formador.

(iii) Literatura de cordel, charges, histórias em quadrinhos (HQ) e tirinhas: De acordo com Barbosa e colaboradores (2011), a literatura de cordel vinculada ao ensino se coloca como um recurso didático auxiliar, com bom potencial didático, sendo inclusive uma ideia inovadora. Acrescentase também o uso de charges, tirinhas e $\mathrm{HQ}$, como importantes meios para a inovação em aulas de Física, possibilitando aos alunos manifestarem diferentes habilidades no processo de aprendizagem. Para Santos (2013), "HQ e tirinhas têm como principal característica a heterogeneidade em que 
se cruzam os textos escritos, oral, sonoro e visual" (p. 39). Nas abordagens realizadas com os licenciandos em IEF, foram construídas charges, HQ e tirinhas utilizando plataformas virtuais da internet. Realizadas as oficinas, os licenciandos foram convidados a produzirem suas próprias $\mathrm{HQ}$, tirinhas e/ou charges sobre temas da Física e utilizarem este recurso na elaboração de uma aula sobre um tema da Física (Figura 3).

FIGURA 3

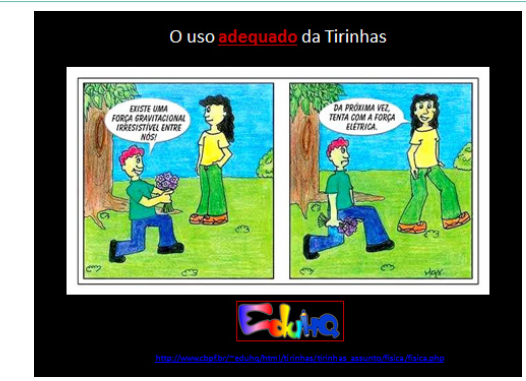

(a)

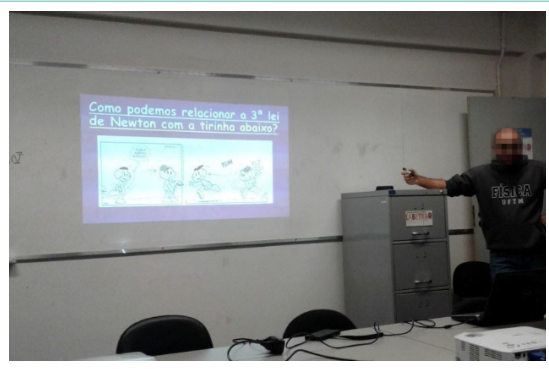

(c)

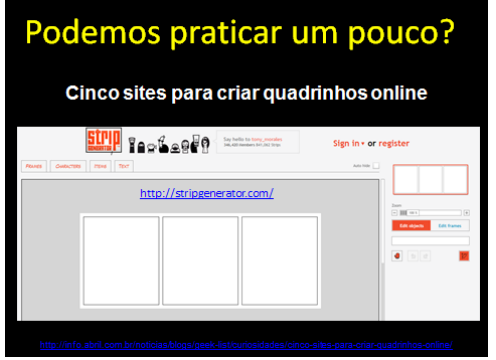

(b)

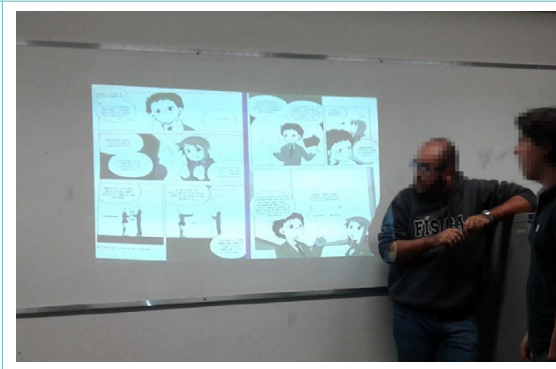

(d)

Em (a) trecho da aula de IEF sobre a temática tirinha e o ensino de Física ministrada pelo professor-formador, com oficina evidenciada em (b). Em (c) o Lic/Fís. A explicando sobre a $3^{a}$ Lei de Newton. Em (d) Lic/Fís. J e Lic/Fís. A discutindo sobre uma tirinha apresentada e sendo avaliado pelo professor-formador.

DESCRIÇÃO DA ATIVIDADE: Esta atividade com foco a ser aplicada no $2^{\circ}$ ano do Ensino Médio teve como objetivo por meio de tirinhas discutirem o conceito de dinâmica.

Foto: professor-formador.

Ademais, no que tange à literatura de cordel (Barbosa, 2011), foi contextualizado com os licenciandos os primórdios desta literatura popular, trazida da Península Ibérica pelos colonizadores e também discutida sua forma construtiva, ou seja, em narrativas poéticas com métrica e rimas soantes. A partir dos aportes teóricos trabalhados pelo professor-formador, os licenciandos foram convidados a criarem seus próprios cordéis sobre um tema da Física de livre escolha (Figura 4). 


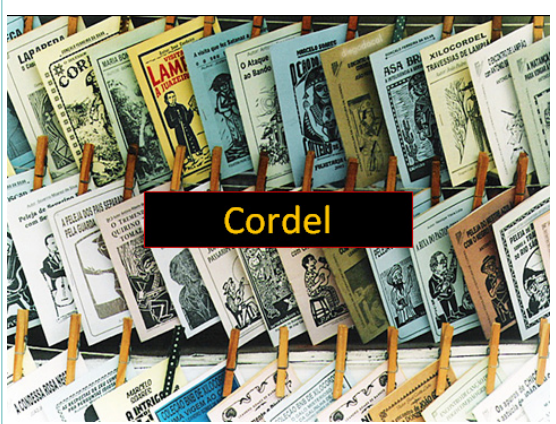

(a)

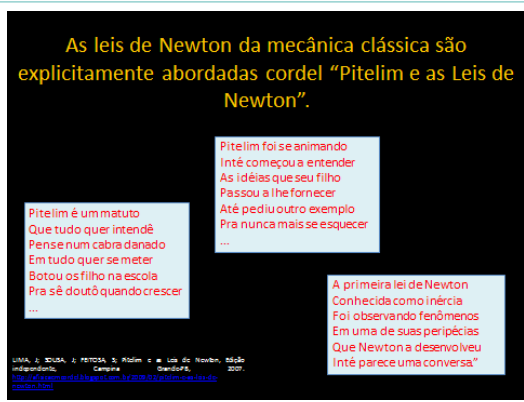

(c)

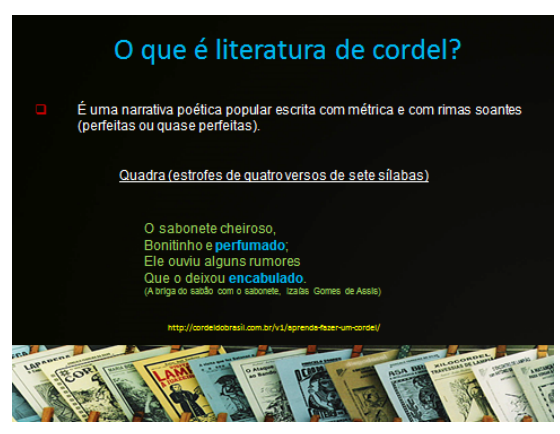

(b)

(d)

Em (a) e (b) trechos da aula de IEF em que o professor-formador explorou o tema literatura de cordel com os licenciandos. Em (c) exemplo de um cordel sobre as Leis de Newton e a Mecânica Clássica. Em (d) um exemplo da utilização de do cordel pelo Lic/Fis. L.

DESCRIÇÃO DA ATIVIDADE: Esta atividade teve como objetivo discutir a literatura de cordel como possibilidades para o ensino de Física com os licenciandos e propor atividades utilizando esta temática.

Fonte: IEF, 2017. Notas de aula.

Outros aspectos metodológicos também foram trabalhados com os licenciandos, como: a elaboração de mapas conceituais (Moreira, 1998) e a metodologia Peer Instruction (PI) (Manzur e Watkins, 2009). Sobre mapas conceituais (MC), estes configuram instrumentos que buscam a sistematização de ideias e significados em torno de um conceito particular e a relação deste conceito com seu entorno teórico. A noção de mapa conceitual deriva das ideias de David Ausubel (1918-2008) sobre a aprendizagem significativa. Sobre a metodologia PI pode ser entendida como uma metodologia de condução das ações didáticas com o fim de promover a efetivo-ativa participação dos alunos no processo de ensino e aprendizagem. Em termos práticos, o professor busca elaborar questões sobre a temática/conceitos a ser discutida e, por meio de flashcards (cartões resposta) ou clickers, os alunos interagem indicando a resposta que julgar correta. 
Os procedimentos didáticos descritos referem-se aos trabalhos desenvolvidos com os licenciandos na disciplina IEF, na Universidade, e vislumbraram contribuir com a formação docente e com a inovação no ensino de Física a partir da tríade arte-ciência-cultura. Paralelamente a estes trabalhos, alguns licenciandos que cursavam a disciplina ECS IV escolheram um dos tópicos trabalhados para o desenvolvimento de $\mathrm{OE}$ a ser aplicado em sala de aula em seus momentos de regência supervisionada.

\section{AVALIAÇÃO DOS PROCESSOS DE APRENDIZAGEM DOS LICENCIANDOS}

Buscando acompanhar o processo de construção do conhecimento do aluno, em ambas as disciplinas foram seguidas as ideias de avaliação formativa, na qual se preza pela aprendizagem significativa frente ao processo em que ocorre o ensino (Quadros 3 e 4). 0 intuito foi propiciar ao licenciando novas vivências e oportunidades de aprendizagem, assim buscou-se também trabalhar diferentes formas de avaliação, de modo a valorizar as competências e habilidades de cada um, como escrita, comunicação e expressão, artes, criatividade, criticidade, conhecimento conceitual, participação e assiduidade.

\section{QUADRO 3}

Processo avaliativo em Instrumentação para o Ensino de Física (IEF)

\begin{tabular}{|l|l|}
\hline \multicolumn{1}{|c|}{ Ações/atividades } & \multicolumn{1}{c|}{ Processo avaliativo (viés de aprendizagem) } \\
\hline $\begin{array}{l}\text { Atividades Investigativas, aspectos } \\
\text { teóricos, práticose oficina de discussão. } \\
\text { Experimentação e o Ensino de Física. }\end{array}$ & $\begin{array}{l}\text { Participação escrita e dialogada no desenvolvimento e } \\
\text { apresentação de atividades investigativas em sala de } \\
\text { aula com o uso de materiais de baixo custo. }\end{array}$ \\
\hline $\begin{array}{l}\text { O uso de filmes, teatro e música como } \\
\text { estratégias didáticas para o Ensino } \\
\text { de Física. }\end{array}$ & $\begin{array}{l}\text { Análise de trecho de filmes, análise de músicas bus- } \\
\text { cando discutir a História e Filosofia da Ciência e os } \\
\text { conceitos físicos envolvidos nestas produções. }\end{array}$ \\
\hline $\begin{array}{l}\text { O uso de charges, tirinha e literatura de } \\
\text { cordel como estratégias didáticas para } \\
\text { O Ensino de Física. }\end{array}$ & $\begin{array}{l}\text { Produção de tirinhas e/ou charges sobre temas variados } \\
\text { da Física. Produção de literatura de cordel. Apresen- } \\
\text { tação de tais produções para os pares em sala de aula. }\end{array}$ \\
\hline $\begin{array}{l}\text { Mapas conceituais (MC) e seu uso na } \\
\text { educação, aspectos teóricos, práticos } \\
\text { e oficina de elaboração de MC. }\end{array}$ & $\begin{array}{l}\text { Elaboração de mapas conceituais sobre temas de inte- } \\
\text { resse particular e da Física e apresentação dos mapas } \\
\text { para os pares em sala de aula. }\end{array}$ \\
\hline $\begin{array}{l}\text { Peer Instruction (Instrução em pares). } \\
\text { participação dialogada e por escrito utilizando a }\end{array}$ & $\begin{array}{l}\text { Partodogia Peer Instruction. Análise das respostas e } \\
\text { entendimentos conceituais dos alunos. }\end{array}$ \\
\hline $\begin{array}{l}\text { Aspectos finais de avaliação: Elaboração e entrega de um plano de aula prévio, a partir da } \\
\text { escolha de um “instrumento didático" trabalhado em IEF tendo como foco sua aplicação em } \\
\text { sala de aula em ECS IV. }\end{array}$
\end{tabular}


QUADRO 4

Processo avaliativo em Estágio Curricular Supervisionado IV (ECS IV)

\begin{tabular}{|c|c|}
\hline Ações/atividades & Processo avaliativo (viés de aprendizagem) \\
\hline $\begin{array}{l}\text { Aportes teóricos a partir do trabalho } \\
\text { com textos extraído de artigos, livros } \\
\text { versando sobre oestágio supervisionado } \\
\text { em cursos deformação de professores. }\end{array}$ & $\begin{array}{l}\text { Participação dialogada nas discussões durante as aulas. } \\
\text { Posicionamentos frente às discussões e/ou entrega } \\
\text { de resenha ou análise crítica dos textos trabalhados. }\end{array}$ \\
\hline $\begin{array}{l}\text { Apresentação e discussão da temática } \\
\text { "Objetos Educacionais" e seu uso na } \\
\text { educação a partir de textos extraído de } \\
\text { artigos, livros e domínios eletrônicos da } \\
\text { internet. Orientação sobre os relatórios } \\
\text { de estágio. }\end{array}$ & $\begin{array}{l}\text { Participação dialogada nas discussões durante as a } \\
\text { Escolha de um objeto educacional em consonâ } \\
\text { com as discussões realizadas em IEF. Socializaçã } \\
\text { objeto educacional entre os pares, em sala de } \\
\text { Elaboração final de um plano de aula (Anexo 1) } \\
\text { desenvolvimento do objeto educacional. Entreg } \\
\text { relatório parcial de estágio. }\end{array}$ \\
\hline $\begin{array}{l}\text { to de dados } \\
\text { á o estágio. } \\
\text { o e imersão }\end{array}$ & $\begin{array}{l}\text { o do contexto escolar em } \\
\text { bre os aspectos da escola: } \\
\text { público escolar atendido, } \\
\text { ificidades da escola. }\end{array}$ \\
\hline $\begin{array}{l}\text { Orientações e discussão de planos de } \\
\text { aula dos alunos com foco no estágio } \\
\text { de regência e aplicação do objeto } \\
\text { educacional trabalhado em IEF. }\end{array}$ & $\begin{array}{l}\text { Apresentação em Power Pointe dos feedbacks das } \\
\text { aplicações em dos objetos educacionais aplicados } \\
\text { nas escolas. Entrega do caderno de campo utilizado } \\
\text { no decorrer do estágio. }\end{array}$ \\
\hline \multicolumn{2}{|c|}{$\begin{array}{l}\text { Aspectos finais de avaliação: Acompanhamento integral, pelo professor-formador, das regên- } \\
\text { cias nas escolas com a aplicação do objeto educacional desenvolvido em IEF. Socialização } \\
\text { em sala de aula com os pares das regências realizadas. Entrega do relatório final de estágio } \\
\text { supervisionado. }\end{array}$} \\
\hline
\end{tabular}

Buscou-se, por meio deste planejamento, possibilitar aos futuros docentes oportunidades para que se mobilizem em torno do fenômeno educativo, também na perspectiva do desenvolvimento profissional (BOLÍVAR, 2016). Para tanto, almejou-se ampliar a autonomia do futuro licenciando como maneira para reforçar o papel da escola e envolvimento dos professores na contextualização e no enriquecimento do currículo proposto em nível nacional, ou seja, na (re)construção do currículo que desenvolvem.

Ações como as descritas desenvolvem, no contexto escolar, novos significados no âmbito de construção da autonomia, pois este processo implica formas de envolver os diferentes segmentos da comunidade do entorno escolar, constituindo-se como um meio de a escola iniciar um movimento de repensar suas lógicas de uniformidade, daí a necessidade de esse âmbito ser trabalho na formação inicial, no âmbito do desenvolvimento profissional. A seguir, apresentamos os OEs desenvolvidos em IEF pelos Lic/Fis. F e Lic/ Fis. L, com foco no uso de filmes, e aplicados em suas regências supervisionadas no ESC IV. 


\section{APLICAÇÃO DO OBJETO EDUCACIONAL "FILMES" PARA O ENSINO DE FÍSICA}

Na primeira regência, o Lic/Fis. F buscando a inovação metodológica no ensino de Física escolheu trabalhar com o filme "Frankenweenie" e o conteúdo curricular de Física foi "Eletricidade" (Figura 5). O plano de aula foi discutido e produzido em IEF e as prévias das apresentações realizadas na disciplina ECS IV, antes de ir para a sala de aula do Ensino Médio. A aplicação da atividade foi realizada com uma sala de $3^{\circ}$ ano do Ensino Médio em uma escola pública estadual da cidade de Uberaba/MG, com duração de duas aulas duplas (04 aulas).

\section{Figura 5}
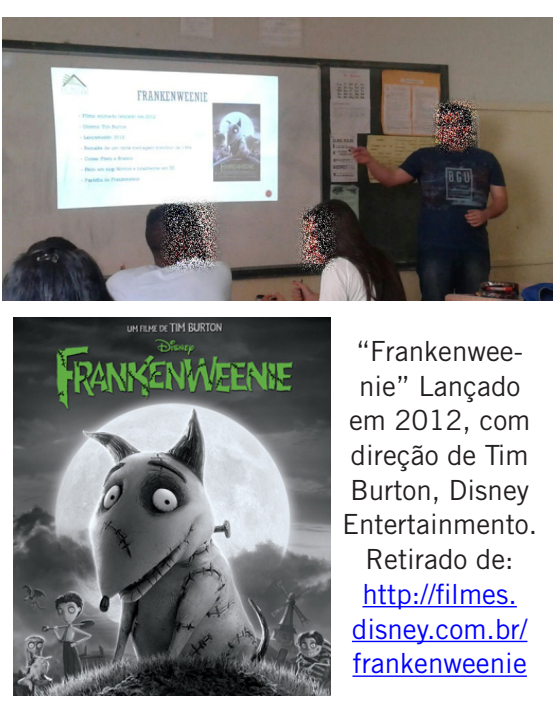

(a)

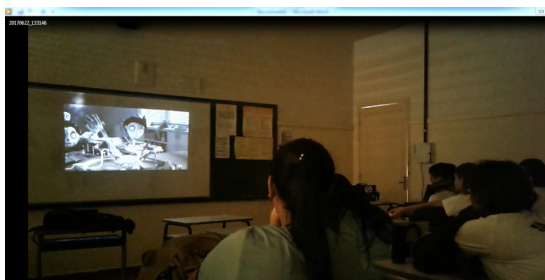

(b)

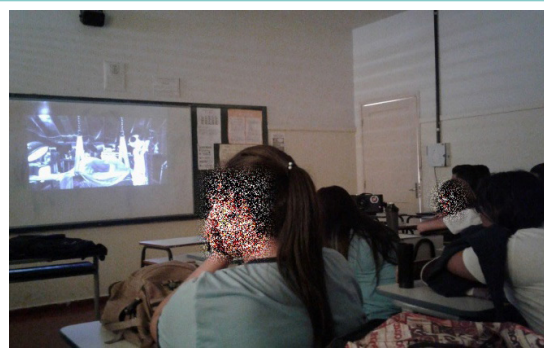

(c)

(a) Apresentação do Lic/Fis. F sobre o filme Frankenweenie aos alunos; (b) personagem Victor Frankestein assiste aula de Ciência em que o professor Sr. Rzykruski ensina sobre bioeletricidade, aplicada a uma rã; (c) Victor Frankestein inconformado com a morte do cachorro Sparky decide tentar ressuscitá-lo com o que aprendeu em sala de aula.

Fonte: professor-formador.

Inicialmente o licenciando apresentou o filme para os alunos em duas aulas, mediando para que atentassem para momentos do filme que propiciassem discussões sobre os conteúdos de Física escolhidos (Figura 5b, 5c). Após a exibição do filme, nas duas aulas seguintes, o licenciando passou a sistematizar os conteúdos de eletricidade na lousa e fazer relações com cenas do filme apresentado. Desta forma, conduziu uma aula dialogada, sempre buscando interligar aspectos da Física e da História da Ciência (HFC) 
com as cenas vivenciadas no filme, por exemplo, em indagações do tipo: como relacionar os fatos do filme com o funcionamento de um para-raios? É possível aplicar os conceitos de eletricidade para trazer os mortos de volta à vida?

Frente às atividades realizadas, ficou evidente que a atividade contribui como um chamariz para as discussões sobre os conceitos da Física trabalhados pelo licenciando em sua regência. Desta forma, propiciou uma inovação metodológica muito frutífera para o «ensinar» a Física, fato, constato notado nas percepções do licenciando: "[...] Penso que o cinema, por si só, chama bastante atenção dos alunos. Quando se une isto [filmes] a conteúdos que seriam chatos desses [alunos] estudarem da maneira tradicional, podese então criar aulas mais cativantes e chamativas aos alunos" (Lic/Fis. F).

Destaque-se, neste excerto, que o desenvolvimento de investigações no interior das escolas poderá, já no contexto da formação inicial, constituir-se encaminhamento para erradicação de dicotomias, bem como para integração entre conhecimentos relativos à Física e aqueles de natureza didático-pedagógica, conferindo significado às práticas profissionais em desenvolvimento na escola.

Assim se coloca a necessidade de a formação de professores integrar-se fortemente à escola. Morgado (2011) afirma que, para que uma efetiva mudança de modelo formativo possa ocorrer, é fundamental que a formação ocorra na escola, por isso também a escola precisa estar integrada e ser partícipe na formação dos futuros professores, como no trabalho aqui apresentado. 0 autor afirma que este é o caminho para seja possível romper com o que chama de "“liturgia formativa", que insiste em formar profissionais mais para o terreno da execução do que para os domínios da decisão e da inovação" (p. 808).

Desta forma, o papel desempenhado pelos professores é elemento fundamental à melhoria das instituições educacionais e também da própria educação, mais amplamente. É nessa direção que buscamos intervir, pensando que é necessário aos professores deixarem de se limitar a cumprir as prescrições curriculares, mas estejam inseridos em um processo de renovação e (re)valorização científica e pedagógica, assumindo-se como profissionais autônomos e que trabalham em benefício no conjunto concreto de alunos, como expõe Morgado (2011).

Para a segunda regência, o Lic/Fis. L escolheu relacionar o uso de filmes à atividade experimentação-demonstrativa. A escolha em trabalhar uma atividade do tipo experimental-demonstrativa deveu-se ao fato do licenciando utilizar na aula um gerador de Van der Graff para trabalhar a temática "Eletrostática" com os alunos. Da mesma forma que as aplicações anterio- 
res, o plano de aula também foi discutido e produzido em IEF e as prévias das apresentações realizadas na disciplina ECS IV, antes de ser aplicado no Ensino Médio. A aplicação da atividade foi realizada em uma sala de $2^{\circ}$ ano do Ensino Médio em uma escola particular da cidade de Uberaba/MG, com duração de duas aulas duplas (04 aulas) (Figura 6).

\section{FIGURA 6}

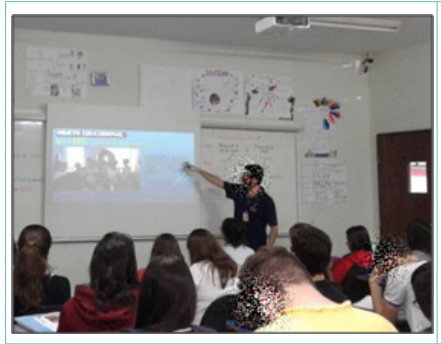

(a)

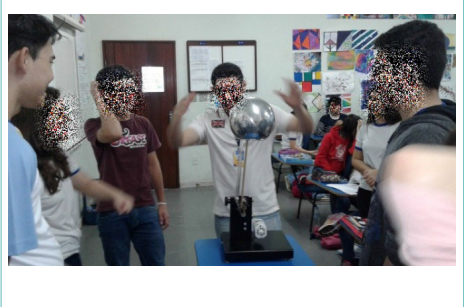

(b)

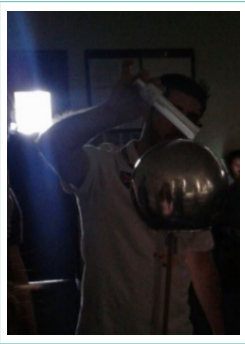

(c)

(a) Lic/Fis. L ministrando os aportes teóricos para a realização da atividade, com base em excetos de filmes/documentários; (b) atividade experimental-demonstrativa, testando as hipóteses levantadas pelos alunos frente à discussão de filme/documentário; (c) lâmpada fluorescente sendo acesa a partir do acúmulo das cargas elétricas na superfície do gerador eletrostático.

Fonte: professor-formador.

Inicialmente, em duas aulas, o licenciando apresentou aos alunos uma cronologia histórica das primeiras máquinas eletrostáticas, de seus usos em Shows de Física, além dos conceitos vinculados a estas apresentações (Figura 6a). Seguindo, o licenciando apresentou e discutiu alguns trechos do episódio "O garoto elétrico", da série Cosmos (série de 1980, produzida pela KCET, Carl Sagan Productions e British Broadcasting Corporation - BBC) na qual é retratada a história de Michael Faraday (1791-1867) e a Física. Também nestas aulas foram apresentados trechos de videoclipes associando utilizando experimentos de Física e Rock and Roll. As duas aulas seguintes foram dedicadas à apresentação experimentação-demonstrativa do gerador de Van der Graff (Figura 6b).

Nestas aulas o licenciando atuou como mediador entre o conhecimento fazendo com que trabalhassem de forma investigativa para responder as questões por ele formuladas. Desta forma, os alunos discutiam as questões colocadas, levantavam hipóteses e o licenciando socializava com a sala testando-as (Figura 6c). A abordagem experimental no ensino de Física é um artifício que o professor pode utilizar para cativar e motivar os alunos para o estudo da Física. Este fato ficou evidente no trabalho realizado pelo licenciando, visto que a participação dos alunos foi uma constante durante todas as aulas desenvolvidas. Um fato não apenas percebido pelo professor-formador, mas também pelo próprio licenciando, por exemplo, quando expressa que: 
"[...] [sobre] a realização das aulas de atividades experimentais, penso que foi de suma importância e significativa para a aprendizagem dos alunos, e, a forma no qual conduzi as atividades experimentais e o conteúdo foi muito satisfatório" (Lic/Fis. L).

Portanto faz-se necessário trabalhar, no âmbito da formação inicial, um novo conceito de currículo, mais consonante com as demandas atuais, quer dizer, compreendido como projeto social e como processo deliberativo, flexível e integrado. Este olhar coloca-se de modo contrário ao conceito de currículo em geral presente nos sistemas de ensino: "[...] um currículo espartilhado, delimitado por territórios disciplinares bem vincados, onde 0 primado da sequencialidade determina e impõe o conhecimento a ministrar ao aluno" (Morgado, 2011, p. 807). Trata-se de assumir uma concepção de currículo voltada à construção coletiva de conhecimentos, organizada mais diretamente quanto às necessidades e exigências sociais contemporâneas do que propriamente nas disciplinas escolares.

Por fim, os desafios que se colocam em âmbito curricular demandam professores que apresentem iniciativa e decisão, que compreendam a concepção e o uso de metodologias inovadoras. Busca-se, também, que adequem os processos de ensino-aprendizagem às características e motivações dos alunos com que trabalham, talvez diferentes daqueles da época em que o professor era aluno. Trata-se de um pressuposto que requer uma formação que seja mais protagonista e interventiva para os próprios formandos, a ser desenvolvida desde a etapa inicial de formação.

\section{CONSIDERAÇÕES FINAIS}

O propósito de inovação nos domínios escolares não é uma tarefa das mais fáceis, haja vista a complexidade do sistema educacional. Assim, atentar para a formação inicial do professor, pilar que sustenta grande parte das variáveis envolvidas nos processos de ensino e aprendizagem torna-se, então, uma estratégia promissora. É justamente neste contexto que se insere esta contribuição.

Com o intuito de propiciar na formação inicial do professor novas formas de ensinar a Física, foi realizado este trabalho na tríade arte-ciênciacultura, o qual envolveu aspectos conteudistas, metodológicos e de inovação avaliativa. As abordagens realizadas evidenciaram possibilidades da concretização de trabalhos interdisciplinares, em uma (re)leitura da Ciência, em particular a Física, não desvinculadas de outras vertentes educacionais, como: artes, literatura, filosofia, história e português. Esta é uma ação con- 
sonante com o proposto em diferentes documentos, como a Lei de Diretrizes e Bases da Educação (BRASIL, 1996), que sinaliza a interdisciplinaridade como elemento indispensável para que o cidadão entenda e interprete o que se aprende na relação com o que vive.

Inicialmente faz-se necessário implementar políticas educativas e curriculares que possibilitem a autonomia dos professores e das unidades educacionais e promovam mudanças as quais, em consonância com Hargreaves (2016), sejam sustentadas e sustentáveis. Sustentadas porque precisam considerar os planejamentos locais, específicos de cada escola, em suas interfaces com o que é diretriz nacional ou internacional, e sustentáveis no sentido de potencializar inovações que perdurarem no espaço e no tempo, incidindo sobre a aprendizagem.

Derivou do acompanhamento e supervisão das regências que os licenciandos cumpriram plenamente os objetivos didáticos traçados nas componentes curriculares IEF e ECS IV, sendo a aplicação em sala de aula do Ensino Médio a culminância do trabalho iniciado na Universidade. Desta forma, é possível expressar que, frente ao trabalho e à avaliação do processo de aprendizagem dos licenciandos, a tríade arte-ciência-cultura contribuiu com a melhoria da formação do licenciando em Física e, consequentemente, com seu trabalho em salas de aulas da Educação Básica. Acrescenta-se o fato de que as regências deram novas roupagens para o trabalho com conteúdos tradicionais da Física. Dentre as contribuições deste trabalho, destacam-se:

a) Para o professor-formador: a oportunidade de ampliar seu desenvolvimento profissional, agregando a possibilidade de estreitar o diálogo entre a Universidade e a sociedade. Também, vivenciar as angústias e dilemas da profissão docente no chão da escola, por meio do acompanhamento do estágio supervisionado. Ademais ampliar a possibilidade de pesquisas na Educação Básica.

b) Para a formação do licenciando: ser uma oportunidade de refletir, ainda na formação inicial, sobre novas formas de ensinar a Física, provocando o desejo em inovar a prática docente, atentando-se para o seu próprio desenvolvimento profissional. Pode, inclusive, contribuir para que os alunos vejam a Física presente no cotidiano, produto da construção humana, não como obra de "gênios isolados".

c) Para a sociedade: destaca-se que ao propiciar uma formação mais sólida ao futuro professor, toda a sociedade é contemplada. Ademais, a constatação de que os resultados nos exames nacionais de avaliação na componente "Ciências da Natureza", em especial no que concerne à componente Física, estão aquém 
do desejável, retrata a realidade do atual sistema educacional brasileiro. As ações desenvolvidas buscam propiciar uma sólida formação do professor, de modo a propiciar o trabalho com conteúdos da Física de modo contextualizado com o cotidiano e interdisciplinar.

d) Para os alunos da Educação Básica: educar é valorizar as diferentes formas de expressão e comunicação. O fascínio que as artes e cultura exercem sobre os alunos e a facilidade que muitos alunos têm de trabalhar com diferentes formas de expressão são elementos que justificam este trabalho com o licenciando, futuro professor.

Cabe destacar que dificuldades são inerentes a qualquer processo de inovação. Sobre este aspecto e, contribuindo com a replicação desta proposta por colegas professores-formadores, destaca-se a dificuldade em muitos cursos de licenciatura de atrelar atividades desenvolvidas em disciplinas distintas, mesmo que correlatas, dentro do curso. Na presente experiência este fato foi atenuado (e possível) visto que ambas as disciplinas foram ministradas pelo mesmo professor-formador. Outra dificuldade refere-se ao perfil dos alunos dentro dos cursos, os quais, no caso particular da licenciatura em Física, nem sempre percorrem a sequência traçada no PPC. Assim, talvez, possa dificultar este trabalho, sendo necessárias adequações em sua elaboração e execução. Contudo, conjetura-se que tais dificuldades possam ser contornadas a partir do trabalho conjunto entre professores-formadores dentro do mesmo curso e do planejamento junto aos alunos para o trabalho continuo na formação inicial. No presente caso, as ações proporcionaram novas vivências aos licenciandos em relação aos conceitos trabalhados na Universidade e culminando com inovações metodológicas em salas de aula do Ensino Médio. Finalmente, como cita Bolívar (2016), a mudança se processa no que os sujeitos [são] capazes de pensar e fazer com ela, o que reitera o fato de que a mudança da escola pública deve ser pensada e executada com os professores e não simplesmente para os professores.

\section{REFERÊNCIAS}

Alves Ferreira, R. et al. (2009). Cinema e ensino de física. In.: XVIII Simpósio Nacional de Ensino de Física, Vitória, ES, 2009. Recuperado de: http://www.cienciamao.usp. br/dados/snef/ cinemaeensinodefisica.trabalho.pdf

Araujo, M. S. T. \& Abib, M. L. V. S. (2003). Atividades Experimentais no Ensino de Física: Diferentes Enfoques, Diferentes Finalidades. Revista Brasileira de Ensino de Física. 25(2), 176-194. 
Barbosa, A. S. M., Passos, C. M. B. \& Coelho, A. A. (2011). O cordel como recurso didático no ensino de ciências. Experiências em Ensino de Ciências, 6(2), 161-168.

Bolívar, A. (2016). ¿Cómo puede la evaluación institucional contribuir para mejorar la escuela? Estudos em Avaliação Educacional, São Paulo, 27(65), 284-313.

Brasil (1996). Lei de Diretrizes e Bases da Educação. Lei n 9394/96, de 20 de dezembro de 1996. Ministério da Educação. Brasília: MEC. Recuperado de: http://www.planalto. gov.br/Ccivil_03/leis/L9394.htm

Brasil (2002). Orientações Educacionais Complementares aos Parâmetros Curriculares Nacionais. PCN+ Ensino Médio. Ministério da Educação. Brasília: MEC. Recuperado de: http:// portal.mec.gov.br/seb/arquivos/pdf/book_volume_02_internet.pdf

Canário, R. (2002). Formação inicial de professores: que futuro(s)? In: Afonso, N. \& Canário, R. Estudos sobre a situação da formação inicial de professores. Porto: Porto Ed., 37-63.

Carvalho, A. M. P. (2013). Ensino de Ciências e a proposição de sequências de ensino investigativas. In: Carvalho, A. M. P. (Org.). Ensino de Ciências por Investigação. $1^{\text {a }}$ ed. São Paulo: Cengage Learning.

Ferreira, M. (2013). Como usar a música na sala de aula. São Paulo: Contexto, 8a ed., 238p.

Fortunato, I. (2017). Entrevista com Francisco Imbernón. Revista Internacional de Formação de Professores (RIFP), Itapetininga, 2(2), 184-188.

Gallego Dominguez, C. \& Marcelo Garcia, C. (2018). ¿Quién soy yo como maestro? Construcción de la identidad profesional en docentes principiantes. Identidad profesional docente. Narcea, p. 46-61.

Hargreaves, A. (2016). The place for professional capital and community. Journal of Professional Capital and Community, 1(1). Recuperado de: https://doi.org/10.1108/ JPCC-11-2015-0010

Laville, C; Dionne, J. (1999). A construção do saber: manual de pesquisa em ciências humanas. Porto Alegre: Editora Artes Médicas.

Mazur, E. \& Watkins, J. (2009). Just-in-Time Teaching and Peer Instruction. Getting Started with Just-in-Time Teaching. Recuperado de: http://www.stat.columbia.edu/ gelman/ communication/WatkinsMazur2009.pdf

Medeiros, Z. (2016). Entrevista com Manuela Esteves. Revista Docência Ensino Superior, 6(2), $275-$ 288. Recuperado de: https://seer.ufmg.br/index.php/rdes/article/view/3726/2757

Moreira, M. A. (1998). Mapas conceituais e aprendizagem significativa. Cadernos de Aplicação, Porto Alegre, 11(2), 143-156.

Moreira, A. F. B. \& Ramos, R. K. (2016). Mobilidade educacional e a internacionalização dos estudos curriculares. Revista Teias (UERJ. Online), 17(45), 163-175, 2016.

Morgado, J. C. (2011). Identidade e profissionalidade docente: sentidos e (im)possibilidades. Ensaio, Rio de Janeiro, 19(73), 793-812.

Munford, D. \& Lima, M. E. (2007). Ensinar ciências por investigação: em quê estamos de acordo? Revista Ensaio Pesquisa em Educação em Ciências. 9(1), 72-89.

Napolitano, M. (2013). Como usar o cinema na sala de aula. São Paulo: Contexto, $5^{a}$ ed., 251 p. 
Pacheco, J. A (2016). Para a noção de transformação curricular. Cadernos de Pesquisa, 46(159), 64-77.

Piassi, L. P. \& Pietrocola, M. (2009). Ficção científica e ensino de ciências: para além do método de encontrar erros em filmes. Educação e Pesquisa, São Paulo, 35(3), 525-540.

PPC/Física/UFTM (2010). Projeto Pedagógico Curso de Graduação em Física - Licenciatura. Universidade Federal do Triângulo Mineiro. Uberaba, Brasil. Recuperado de: http:// www.uftm.edu.br/fisica/projeto-pedagogico

Roldão, M. C. (2017). Conhecimento, didáctica e compromisso: o triângulo virtuoso de uma profissionalidade em risco. Cadernos de Pesquisa, 47(166), 1134-1149. 
